\title{
NOTIFICATIONS OF DANGEROUS PRODUCTS FROM EUROPEAN UNION COUNTRIES IN THE RAPEX AS AN E-SERVICE
}

\section{MARCIN PIGŁOWSKI}

Gdynia Maritime University, POLAND

e-mail: m.piglowski@wpit.am.gdynia.pl

RECEIVED
ACCEPTED
JEL
CLASSIFICATION

KEYWORDS

ABSTRACT

\author{
4 July 2017 \\ 15 December 2017 \\ C38, F15, K32, L67, L68
}

non-food products, consumer safety, common market, cluster analysis, scatterplots

The Rapid Alert System for dangerous non-food products (RAPEX) may be considered as a type of e-service, which combines e-administration, e-education and e-health. The RAPEX enables quick exchange of information between national authorities of the European Union (EU) countries on measures taken against products posing a risk to consumers health and safety. In the period 2005-2016 the notifications in the RAPEX related mainly to products originated from China (57\%), however, notifications to products from EU countries accounted for $18 \%$ of all notifications. Therefore, the goal of the study was to examine, which product categories from EU countries were most commonly submitted in the RAPEX and which was the dependence between product category and origin country, year, risk level, product user, submitting country, risk type and adopted measures. There were cluster analysis and scatterplots using Statistica 12 and pivot tables using Excel applied. The largest number of notifications was submitted to products from Germany, but also from France, Italy, United Kingdom and Poland. There were mainly motor vehicles (and the number of notifications increased last years) and also clothing, textiles and fashion items, childcare articles and children's equipment, toys and cosmetics. The product user was mainly consumer. The risk level was primarily serious and the risk type was injury. The products were most often submitted by Germany and also Greece and the appropriate measures to products were taken mainly by economic operators.

\section{Introduction}

The service, which is provided via the internet can be defined as an electronic service (e-service) (see Szopiński, 2012). The development of e-services is considered by the European Union (EU) as a manifestation of building an information society, an orientation to meet the needs of society and a rising standard of living. The Rapid Alert System for dangerous non-food products (RAPEX) may be considered as type of e-service, which combines 
e-administration (use of information and telecommunications technologies in public administration), e-education (use of the internet to obtain information) and e-health (support for all health-related activities) (see Dabrowska, Janoś-Kresło, Wódkowski, 2009).

The RAPEX enables quick exchange of information between EU countries, Iceland, Liechtenstein and Norway and the European Commission about non-food products found on the market and posing a risk to health and safety of consumers (European Commission, 2017). The legal basis for RAPEX is directive 2001/95/EC on general product safety (European Parliament \& Council, 2002). This system covers majority of non-food products, however, products such as pharmaceuticals and medical devices are covered by other alert systems (European Commission, 2014). The information on dangerous products are exchanged between national authorities. The notification is an alert submitted by national authority and concerns measures taken against these products (European Union, 2017).

The RAPEX can be considered as a reactive tool within market surveillance actions (see Alén Cordero, Muñoz Sanz, 2009). The data provided by the RAPEX can be helpful for: customers (wondering about purchase of a product), companies (developing new products or assessing existing ones), consumer organizations (gathering information within tests) and authorities (to reduce risk and to ensure co-coordinated actions) (Rausand, Utne, 2009).

The results obtained from the RAPEX database for the years 2005-2016 indicated that $57 \%$ of notifications related to products from China (European Commission, 2017). This problem was noticed, for example, by Wynn, Ouyang, ter Hofstede, and Fidge (2011), who drew attention to toys originating from China and Tse and Tan (2012), who mentioned that most of the recalled products in the United Kingdom were made in China. However, the notifications to products from EU countries were 18\% (European Commission, 2017) and were not widely discussed. Therefore, the goal of the study was to examine, which product categories from EU countries were most commonly submitted in the RAPEX and which was the dependence between product category and origin country, year, risk level, product user, submitting country, risk type and measures (adopted by submitting country).

\section{Data and methods}

The data originated from the RAPEX database and concerned 3,625 notifications covering the period from 2005 (first year in database) to 2016. The data related to eight variables: product category, origin country, year, risk level, product user, submitting country, risk type and adopted measures.

In order to increase the readability of figures (i.e. scatterplots as mentioned below), it was necessary to adopt certain simplifications. Some values of variable product category were shortened to: "childcare articles..." (name in database: childcare articles and children's equipment), "clothing, textiles..." (clothing, textiles and fashion items), "communication... equipment" (communication and media equipment), "electrical appliances..." (electrical appliances and equipment), "gas appliances..." (gas appliances and components), "kitchen... accessories" (kitchen/ cooking accessories).

In case of variables risk type and origin country, due to the possibility of occurring more than one value in one notification, only first value was adopted. In turn, in case of variable adopted measures in one notification was usually one value, however, the values were too varied. Therefore, only two basic values were adopted and they related to adopted measures taken by: public authority or economic operator.

Data has been collected and sorted to eight above mentioned variables in Excel and then transferred to Statistica 12. In case of tree clustering (joining) the following settings were adopted: linkage rule: Ward's method, 
distance measure: Euclidean distance. The Ward's method uses analysis of variance and is regarded as very efficient. The dependences between variable product category and other variables were examined using pivot tables in Excel (not presented) and (bubble) scatterplots in Statistica. The values of the variables that occurred more often were presented as larger bubbles.

\section{Resullts and discussion}

The results of tree clustering were presented in Figure 1. They indicated the similarity in occurrence in pairs the values of variables: year and risk type and risk level and product user. In the case of the first pair it was associated with the occurrence of a large number of notifications in recent years (see also Figure 3). In turn, in the case of the second pair, this was due to the fact that each of both variables (risk level and product user) had only two values (see also respectively Figures 4 and 5), so they were not differentiated.

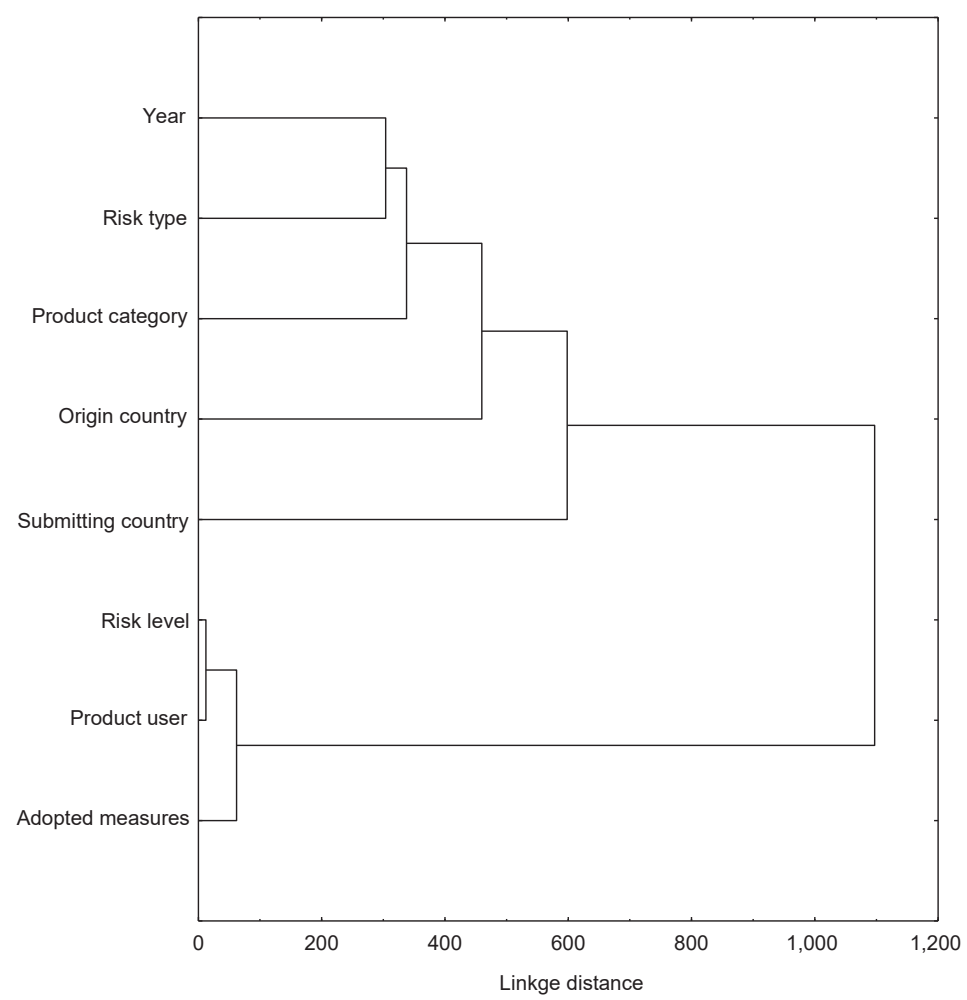

Figure 1. Tree diagram

Source: own study.

The largest number of notifications was submitted to following categories: motor vehicles $(1351 ; 37 \%)$, clothing, textiles and fashion items (429; $12 \%)$, childcare articles and children's equipment $(321 ; 9 \%)$, toys $(297 ; 8 \%)$ and cosmetics (248; 7\%) (European Commission, 2017; European Union, 2017), see also Figures 2-8. 
The dependences between product category and origin country presented in Figure 2.

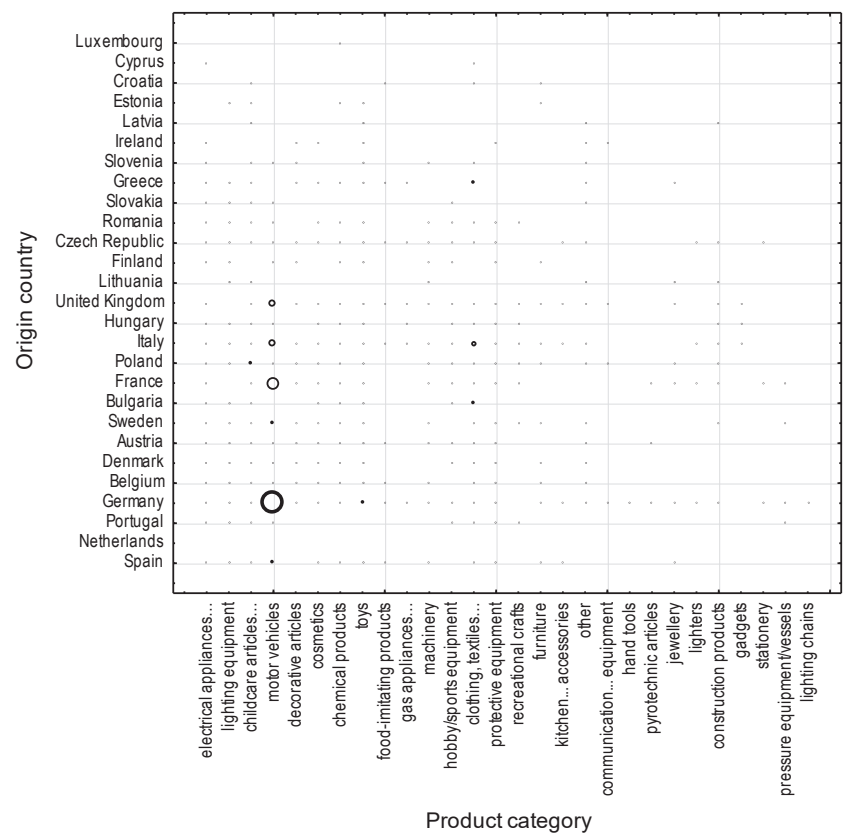

Figure 2. The dependence between product category and origin country

Source: own study.

The largest number of notifications was submitted to products from Germany $(825 ; 23 \%)$, and also to products from Italy (517; 14\%), France (392; 11\%), United Kingdom (312; 9\%) and Poland $(277 ; 8 \%)$.

Notifications to motor vehicles were most visible and to products from Germany were 461 notifications, i.e. about $13 \%$ of all notifications, France - 266; 7\%, United Kingdom - 169; 5\%, Italy - 154; 4\% and Sweden - 81; $2 \%$ (see Figure 2). In case of clothing, textiles and fashion items most notifications related to products from Italy (101; 3\%), Bulgaria (92; 3\%) and Greece (63; 2\%). Most products submitted within category childcare articles and children's equipment originated from Poland $(81 ; 2 \%)$, Italy $(51 ; 1 \%)$ and Germany $(34 ; 1 \%)$, in case of toys - from Germany (79; $2 \%)$, Italy (31; $1 \%)$, Netherlands $(31 ; 1 \%)$, Spain $(31 ; 1 \%)$ and Poland $(30 ; 1 \%)$ and in case of cosmetics - from Germany (43; $1 \%)$, France (36; $1 \%)$ and Italy $(35 ; 1 \%)$.

The dependences between product category and year presented in Figure 3. The highest number of notifications was submitted in 2016 (478, 13\%), but over 300 notifications (about 9\%) were submitted also in 2015, 2014 and earlier in 2012, 2010, 2009 and 2008.

The dependences between product category and risk level presented in Figure 4. The significant part of notifications related to a serious risk - $3545 ; 98 \%$.

The dependences between product category and product user presented in Figure 5. The majority of notification related to products for consumers - 3549; $98 \%$. 


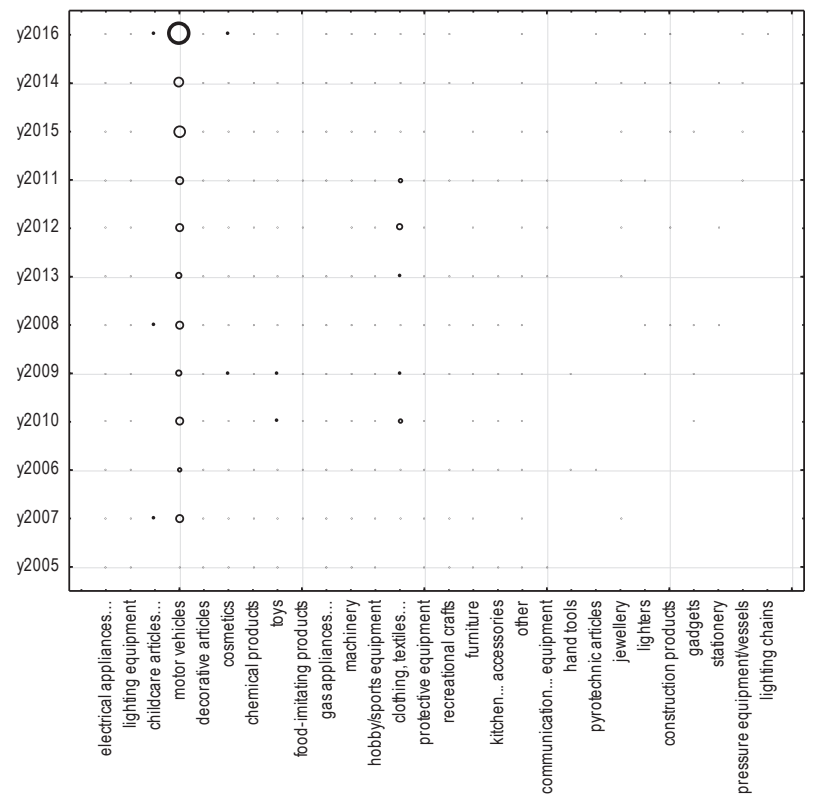

Product category

Figure 3. The dependence between product category and year

Source: own study.

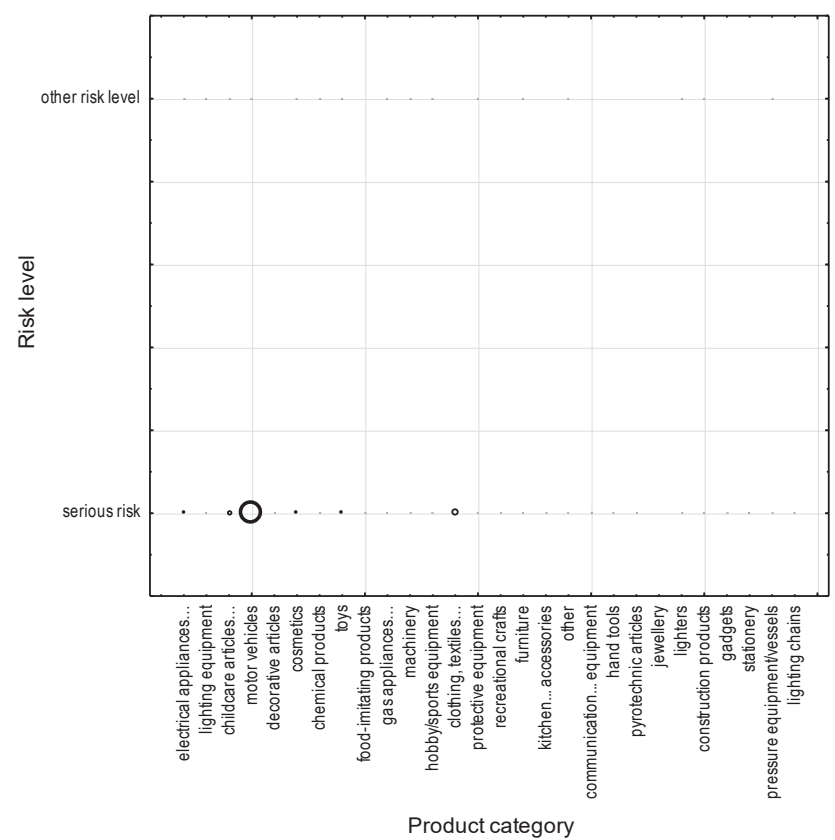

Figure 4. The dependence between product category and risk level

Source: own study. 


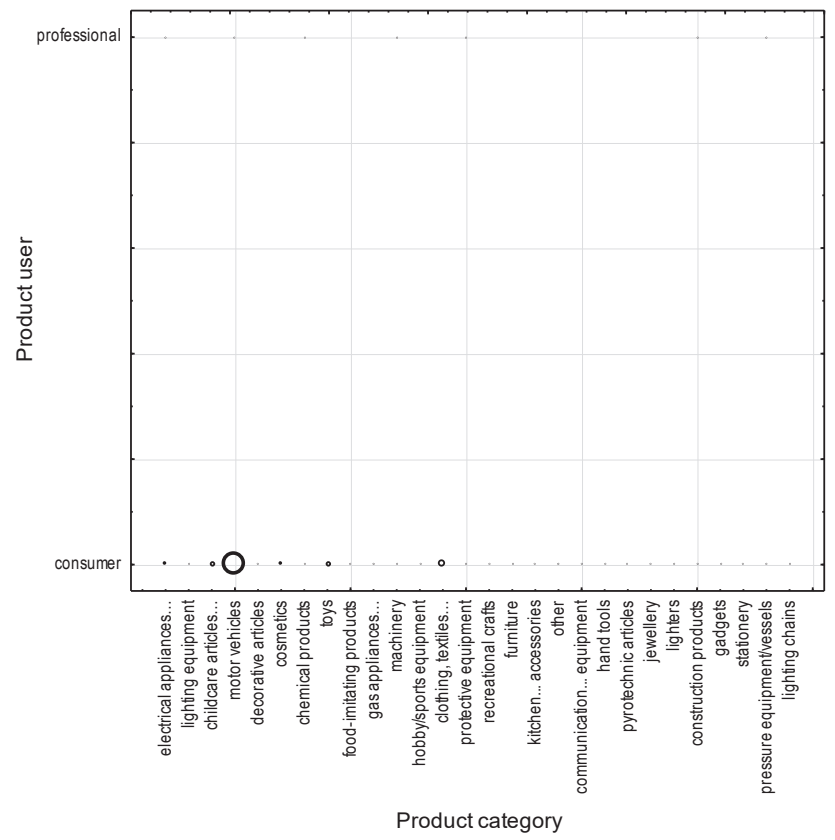

Figure 5. The dependence between product category and product user

Source: own study.

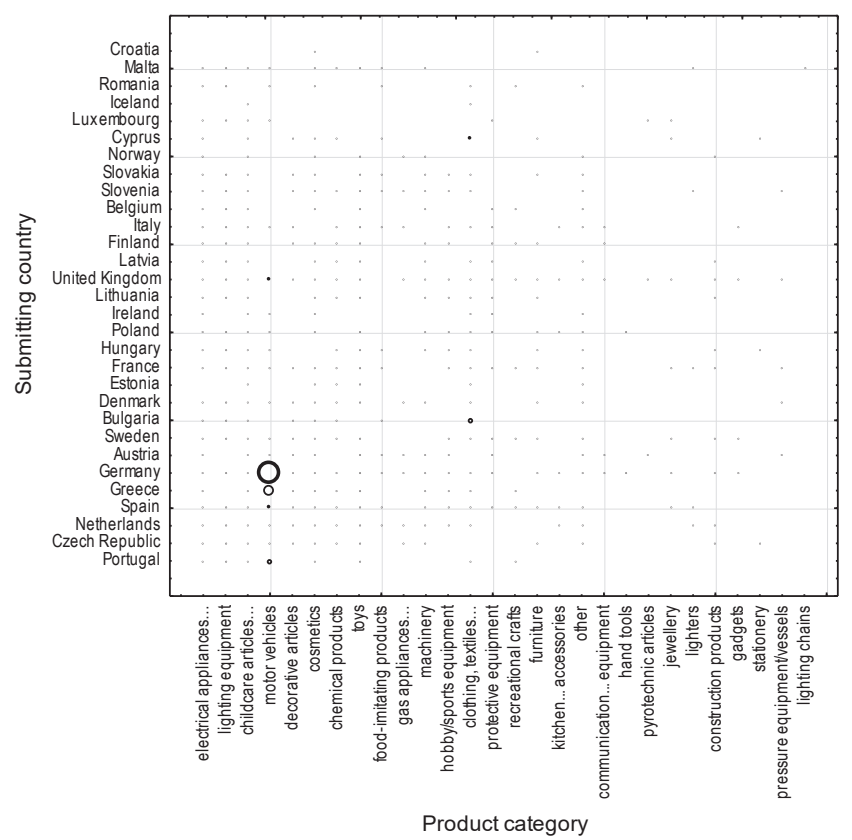

Figure $\mathbf{6}$. The dependence between product category and submitting country

Source: own study. 
The dependences between product category and submitting country presented in Figure 6. Products were submitted mainly by Germany - $825 ; 23 \%$ and also by Greece (358; $10 \%)$, France $(246 ; 7 \%)$, Spain $(240 ; 7 \%)$ and United Kingdom (228; 6\%).

The dependences between product category and risk type presented in Figure 7. The risk type in almost half of notifications was injury - 1691; $47 \%$ and also chemical (528; $15 \%)$, fire (338; $9 \%)$, choking (320; $9 \%)$ and electric shock $(235 ; 6 \%)$.

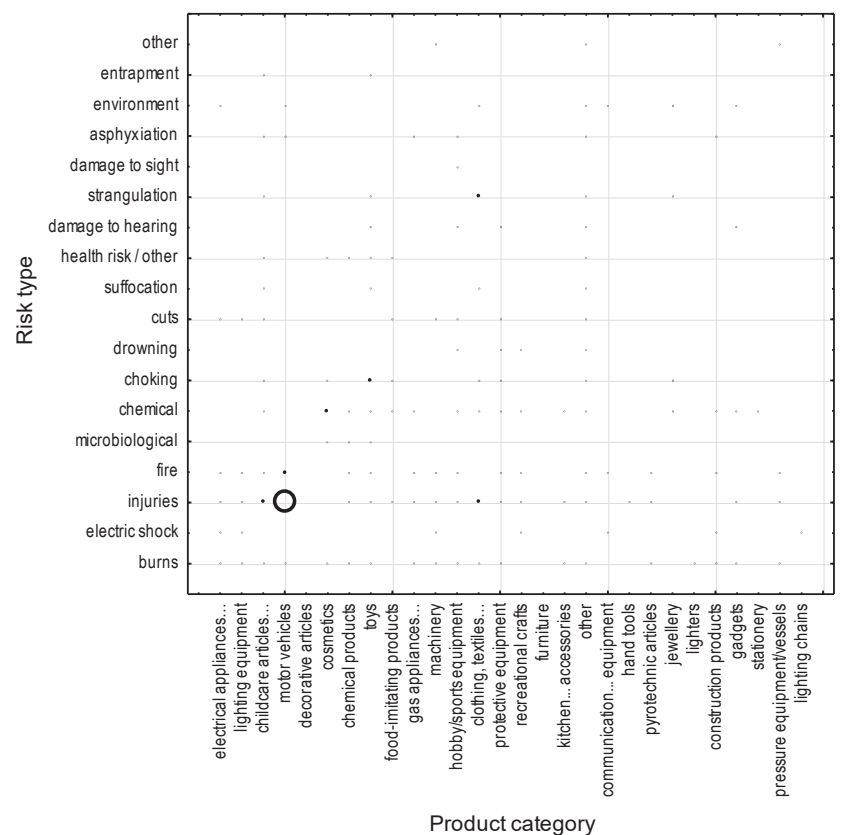

Figure 7. The dependence between product category and risk type

Source: own study.

The dependences between product category and adopted measures to submitted products presented in Figure 8. In more than two third of cases the adopted measures to submitted product were adopted by economic operators (2483; $68 \%$ ) and they were: recall of the product from end users, voluntary corrective actions taken by the manufacturer and withdrawal of the product from the market (European Commission, 2017).

Pose-Juan, Fernández-Cruz and Simal-Gándara (2016) listed similar as above mentioned most frequently submitted products in the RAPEX: toys, motor vehicles, clothing, textiles and fashion items, childcare articles and children's equipment and also electrical appliances (this last category could have been a result of taking into account products from China). Liepina and Korablyova (2014) mentioned about RAPEX notifications on toys. The notifications to cosmetics were indicated by Martin et al. (2011) and Pauwels and Rogiers (2010) directly mentioned about chemical risks in cosmetics. Orford, Crabbe, Hague, Schaper and Duarte-Davidson (2014), without indicating particular products, mentioned about following risks in RAPEX notifications: chemical, but also electrical and 


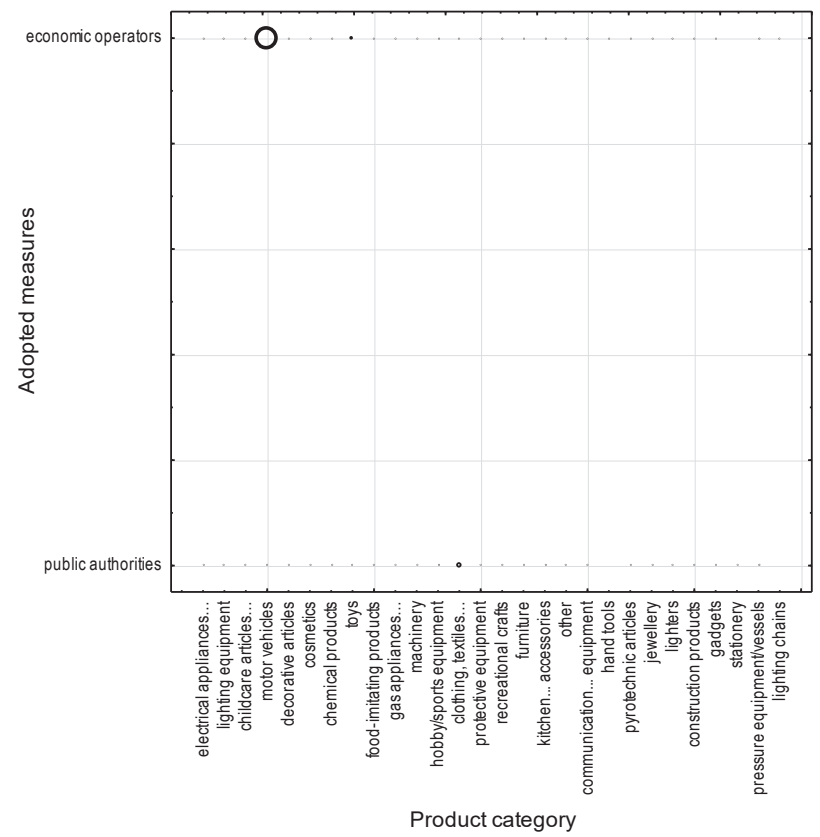

Figure 8. The dependence between product category and adopted measures

Source: own study.

choking. Klaschka (2017) drew attention to the RAPEX notifications related to the chemical risk in personal care products. She added, however, that only health effects considered as serious lead to recall products from consumers. Duarte-Davidson et al. (2014) mentioned that relevant national authorities should be aware of chemical contamination incidents within the RAPEX.

\section{Conclusions}

The Rapid Alert System for dangerous non-food products (RAPEX) ensures rapid exchange of information on dangerous products between national and European Union (EU) authorities and also provides these information in the open access way. Therefore, this system may by considered as a type of e-service (combining e-administration, e-education and e-health) not only for consumers (customers), but also for: producers, distributors, sellers (economic operators), consumer organizations and authorities.

About $18 \%$ of notifications in the RAPEX in 2005-2016 related to products from EU countries. There were mainly notifications on motor vehicles from Germany, but also from France, United Kingdom, Italy and Sweden. The other product groups were: clothing, textiles and fashion items from Italy, Bulgaria and Greece, childcare articles and children's equipment from Poland, Italy and Germany, toys from Germany, Italy, Netherlands, Spain and Poland and cosmetics from Germany, France and Italy.

The highest number of notifications was submitted in 2016. The significant part of notifications related to a serious risk for consumers, not professionals. Products were submitted mainly by Germany and also by Greece, France, Spain and United Kingdom. The risk type was injury, but it were also chemical risks, fire, choking and electric 
shock. The adopted measures were taken mainly by economic operators and they were: recall of the product from end users, voluntary corrective actions of the manufacturer and withdrawal of the product from the market.

The RAPEX as an e-service could be developed by, for example, sending information to consumers in the given EU country related to dangerous products by email, sms or via a smartphone application. Such information should include the exact product name and description and also cover the name of the manufacturer and seller. It would increase the consumer's awareness and safety and would also eliminate unfair business practices on the market.

\section{References}

Alén Cordero, C., Muñoz Sanz, J.L. (2009). Measurement of machinery safety level: European framework for product control: Particular case: Spanish framework for market surveillance. Safety Science, 10 (47), 1285-1296.

Dąbrowska, A., Janoś-Kresło, M., Wódkowski, A. (2009). E-usługi a społeczeństwo informacyjne. Warszawa: Difin.

Duarte-Davidson, R., Orford, R., Wyke, S., Griffiths, M., Amlôt, R., Chilcott, R. (2014). Recent advances to address European Union Health Security from cross border chemical health threats. Environment International, 72, 3-14.

European Commission (2014). Memo/14/214. RAPEX in 2013. Brussels: European Commission.

European Commission (2017). Rapid Alert System for dangerous non-food products. Retreived from: http:/lec.europa.eu/consumers/ consumers_safety/safety_products/rapex/alerts/repository/content/pages/rapex/index_en.htm (18.05.2017).

European Parliament \& Council (2002). Directive 2001/95/EC of 3 December 2001 on general product safety. OJ L 11, 15.1.2002, 4-17.

European Union (2017). Rapid Alert System for dangerous products. Working together to keep consumers safe. 2016 annual report. Luxembourg: Publications Office of the European Union.

Klaschka, U. (2017). Trust, but verify! Personal care products in the rapid alert system database RAPEX. Sustainable Chemistry and Pharmacy, 5, 30-41.

Liepina, R., Korablıva, L. (2014). Market Surveillance of Toys: Situation Assessment and Improvement. Procedia - Social and Behavioral Sciences, Volume 156 (26), 360-364.

Martin, M., Christiansen, B., Caspari, G., Hogardt, A. J., von Thomsen, M., Ott, E., Mattner, F. (2011). Hospital-wide outbreak of Burkholderia contaminans caused by prefabricated moist washcloths. Journal of Hospital Infection, 3 (77), 267-270.

Orford, R., Crabbe, H., Hague, C., Schaper, A., Duarte-Davidson, R. (2014). EU alerting and reporting systems for potential chemical public health threats and hazards. Environment International, 72, 15-25.

Pauwels, M., Rogiers, V. (2010). Human health safety evaluation of cosmetics in the EU: A legally imposed challenge to science. Toxicology and Applied Pharmacology, 2 (243), 260-274.

Pose-Juan, E., Fernández-Cruz, T., Simal-Gándara, J. (2016). State of the art on public risk assessment of combined human exposure to multiple chemical contaminants. Trends in Food Science \& Technology, 55, 11-28.

Rausand, M., Utne, I.B. (2009). Product safety - Principles and practices in a life cycle perspective. Safety Science, 7 (47), 939-947.

Szopiński, T. (2012). E-konsument na rynku usług. Warszawa: CeDeWu.

Tse, Y.K., Tan, K.H. (2012). Managing product quality risk and visibility in multi-layer supply chain. International Journal of Production Economics, 1 (139), 49-57.

Wynn, M.T., Ouyang, C., ter Hofstede, A.H.M., Fidge, C.J. (2011). Data and process requirements for product recall coordination. Computers in Industry, 7 (62), 776-786.

Cite this article aS. Pigłowski, M. (2018). Notifications of dangerous products from European Union countries in the RAPEX as an e-service. European Journal of Service Management, 2 (26), 175-183. DOI: 10.18276/ejsm.2018.26-22. 